\title{
Oxytocin Receptor Gene Polymorphisms in Patients With Diabetes
}

\author{
Ramin Saravani ${ }^{1}$; Elahe Esmaeeli ${ }^{2}$; Mohammad Kordi Tamendani ${ }^{2,}$; Mehrnaz Narooie \\ Nejad $^{3}$
}

${ }^{1}$ Department of Clinical Biochemistry, Cellular and Molecular Research Center, School of Medicilne, Zahedan University of Medica Sciences, Zahedan, IR Iran 2 Department of Biology, University of Sistan and Baluchestan, Zahedan, IR Iran

3 Department of Genetic, Genetic of Non-communicable Disease Research Center, School of Medicine, Zahedan University of Medical Sciences, Zahedan, IR Iran

*Corresponding author: Mohammad Kordi Tamendani, Department of Biology, University of Sistan and Baluchestan, Zahedan, IR Iran. Tel: +98-5412452335, Fax: +98-5412446565, E-mail:dor-kordi@yahoo.com

Received: February 11, 2015; Revised: March 9, 2015; Accepted: March 15, 2015

\begin{abstract}
Background:Type 2 Diabetes(T2D) is a chronic metabolic disease associated with increased mortality and morbidity. High levels of glucose can damage organs, such as the kidneys, eyes and nerves. Oxytocin (OXT) can regulate feeding behavior, energy balance, insulin sensitivity and insulin secretion. The OXT Receptor (OXTR) mediates the action of OXT on cells. The role of OXTR polymorphism in carbohydrate metabolism disorders, especially in T2D, is not clear.

Objectives: The current study aimed to investigate the possible associations between OXTR polymorphism and the risk of developing T2D. Patients and Methods: To study genetic polymorphisms, 120 patients with T2D and 120 controls were selected. Genotyping of the OXTR rs53576 and rs2254298 variants was performed using allele-specific Polymerase Chain Reaction (PCR) and Restriction Fragment Length Polymorphism (RFLP) PCR, respectively. Data were analyzed using Chi-square analysis and logistic regression.

Results: The logistic regression analysis suggested no significant associations of OXTR Single Nucleotide Polymorphism (SNP) rs22542987 in genotypes $(\mathrm{OR}=1.054,95 \% \mathrm{CI}: 0.557-1.995, \mathrm{P}=0.871)$ and alleles of patients with T2D in the study population $(\mathrm{OR}=1.004,95 \% \mathrm{CI}: 0.547-$ $1.845, \mathrm{P}=1)$. The rs53576 polymorphism showed the TT genotype ( $\mathrm{OR}=0.466, \% 95 \mathrm{CI}: 0.22-0.94, \mathrm{P}=0.035)$, as well as $\mathrm{T}$ allele $(\mathrm{OR}=0.66, \% 95$ $\mathrm{CI}:(0.46-0.95), \mathrm{P}=0.03)$ in the patients and control group with a significant difference suggesting the protective role this polymorphism plays in T2D.

Conclusions: Our findings showed that the genotype TT rs53576 OXTR, as well as T allele had significant differences in our population and play a protective role. Therefore, it is suggested to place more interest on these OXTR in large populations and different ethnic groups.
\end{abstract}

Keywords: SNP (Polymorphism); T2D (Type 2 Diabetes); Receptors, Oxytocin; Genes

\section{Background}

Diabetes is the most common endocrine disease and a disorder of carbohydrate metabolism, characterized by high levels of glucose in the blood. Increased blood glucose, resulting from defects in insulin secretion or action, is associated with disturbances in the metabolism of carbohydrates, fats and proteins (1). Nowadays, diabetes is a major threat to global public health and its incidence is on a rise worldwide, being responsible for direct spending of $2.5-15 \%$ of the total health budget in most of countries and for the multiplication of indirect costs $(2,3)$. There are two main types of diabetes: type 1 and type 2 . Type 1 diabetes occurs when insulin-producing cells, pancreatic beta cells, are destroyed, and the body is unable to produce insulin, which must be provided by daily multiple insulin injections for treatment (4). Type 2 Diabetes (T2D) means that the body is still able to produce insulin, although in most cases it is not enough to cover the body's necessities, and becomes evident when the produced insulin, or its cellular receptor, do not work properly, finally leading to insulin therapy after a variable time interval of oral treatment (pills) (5). Patients with T2D that have an unsatisfactory glycemic control (6) may develop common complications of diabetes, namely retinopathy, nephropathy and neuropathy (7). Various studies have shown that social isolation, stress and obesity can be the triggers of Type 2 Diabetes and also, are major risk factors for mortality in humans $(1,8,9)$. Oxytocin (OXT), a nine-amino acid neuropeptide hormone, synthesized in the hypothalamus (10) is implicated in a variety of social behaviors, like the control of stress responses (11), feeding behavior (12), metabolic syndrome (8) and obesity (13), as well as energy balance, such as weight gain or weight loss $(14,15)$. Studies have shown that OXT has anti-diabetic and obesity effects $(16,17)$. Limited evidence indicates an increased oxytocin production in patients with type 1 diabetes (18). Interestingly, OXT is involved in glucose homeostasis by glycogenolysis (19), gluconeogenesis (18) and glycogenesis (20) and also, plays a central role in the control of carbohydrate metabolism in human (21-24) and animal models (25). The OXT can regulate peripheral insulin sensitivity and insulin secretion

Copyright (c) 2015, Zahedan University of Medical Sciences. This is an open-access article distributed under the terms of the Creative Commons Attribution-NonCommercial 4.0 International License (http://creativecommons.org/licenses/by-nc/4.0/) which permits copy and redistribute the material just in noncommercial usages, provided the original work is properly cited. 
$(26,27)$. The actions of OXT are mediated by OXT Receptor (OXTR) that is widely distributed within the brain, including the amygdala, Hypothalamus-Pituitary-Adrenal axis (HPA) $(28,29)$ and peripheral tissue $(30)$. The OXTR gene, located on chromosome 3 , is composed of four exons and three introns. The OXTR gene product is a transmembrane chain of seven domains, belonging to class $1 \mathrm{G}$ proteins (31). Previous obtained data have shown that OXTR activity is necessary for a variety of processes; for example, in the Prader-Willi syndrome, there are deficits of OXT in neurons, while experimental OXTR-deficient animal models show hyperphagia and an increased meal size (32-34). The OXT-OXTR system is necessary for optimal human health. In the recent years, published data showed that genes have an important role in the pathogenesis of T2D (35). Knowledge of polymorphism can be helpful in identifying patients susceptible to T2D disease. However, the role of OXTR polymorphism in carbohydrate metabolism and its effects under various catabolic conditions, especially in T2D, are not clear. Consequently, an investigation on the relationship between OXTR polymorphism and T2D patients, as compared to healthy controls, would be interesting.

\section{Objectives}

In this study the possible correlation between OXTR gene polymorphism and the risk of T2D was evaluated in a sample of the Iranian population.

\section{Patients and methods}

\subsection{Patients}

The protocol of this study was approved by the Ethics Committee of Zahedan University of Medical Sciences, Zahedan, Iran. Subjects were diagnosed with T2D if they had fasting blood sugar of $>126 \mathrm{mg} / \mathrm{dL}, \mathrm{HbA1C}>6.7 \%$ and determined proteinuria and T2D confirmed by a physician. Healthy controls were selected from Ali Asghar Hospital, Zahedan, Iran. Fasting blood sugar of the controls was normal, and they had no family history of diabetes and specific systemic disease. A blood sample was taken from all subjects and collected in Ethylene diamine tetra acetic acid (EDTA)- tubes and stored at $20^{\circ} \mathrm{C}$ until DNA extraction.

Genomic DNA was extracted from peripheral blood of 120 subjects with T2D and 120 healthy controls, using the salting-out method. The DNA extracts were analyzed by electrophoresis. By NanoDrop, DNA concentrations of about $60 \mu \mathrm{g} / \mathrm{ml}$ were obtained and the ratio of 260/280 nm between 1.7 - 1.9 were considered appropriate.

In the OXTR (rs53576) T/C were detected by Allele-Specific Primer (ASP)-Polymerase Chain Reaction (PCR). For OXTR (rs2254298) A/G Restriction Fragment Length Polymorphism-Polymerase Chain Reaction (RFLP-PCR) was used for genotyping. Polymerase Chain Reaction amplifications were performed in a final volume of 20 $\mu \mathrm{L}$. Briefly, $10 \mu \mathrm{L}$ of master mix (ampliqon Taq 2x master mix, Denmark), $0.7 \mu \mathrm{L}$ (10 pmol/mL) of each primer, 2 $\mathrm{mL}$ of template DNA and $6.6 \mu \mathrm{L}$ of DNase-free water were used. For rs53576, the amplification was performed with an initial denaturation step at $95^{\circ} \mathrm{C}$; followed by 30 cycles at $95^{\circ} \mathrm{C}$ for 60 seconds, $56^{\circ} \mathrm{C}$ for 35 seconds, and $72^{\circ} \mathrm{C}$ for 40 seconds with a final extension at $72^{\circ} \mathrm{C}$ for five minutes at $72^{\circ} \mathrm{C}$. For Single Nucleotide Polymorphism (SNP) rs2254298, the cycling conditions were as follow: an initial denaturation step at $95^{\circ} \mathrm{C}$ for five minutes, followed by 30 cycles at $95^{\circ} \mathrm{C}$ for 30 seconds, $62^{\circ} \mathrm{C}$ for 25 seconds, and $72^{\circ} \mathrm{C}$ for 30 seconds with a final extension at $72^{\circ} \mathrm{C}$ for five minutes. For enzymatic digestion, $1.35 \mu \mathrm{L}$ of buffer B 10x, $7 \mu \mathrm{L}$ of PCR product, $0.5 \mu \mathrm{L}$ Bsr1 enzyme, and $11.85 \mu \mathrm{L}$ of DNase-free water were used.

All primer sequences and fragment sizes are listed Table 1. The PCR for the rs2254298 A/G polymorphism was performed using a Forward primer (F) and sequenceReverse primer (R) producing a $307 \mathrm{bp}$ amplicon, and to digested amplification product, the enzyme Bsr1 produced parts G: 9/163/34/101bp and A: 9/163/135 bp (36) (Figure 1). For the rs53576 T/C, PCR was performed using a common Forward primer (F), and two sequence-specific Reverse primers (R1 and R2) creating a 224 bp band for both $\mathrm{T}$ and $\mathrm{C}$ alleles (Figure 2).

Table 1. Allele-Specific Polymerase and Restriction Fragment Length Polymorphism Polymerase Chain Reaction Primer Sequences

\begin{tabular}{lccc}
\hline Primer 5' - 3' & Product & Method & Allele (bp) \\
\hline rs2254298 & $307 \mathrm{bp}$ & RFLP: BsrI & G 9/163/34/101 \\
F: TGAAAGCAGAGGTTGTGTGGACAGG & & & A 9/163/135 \\
R: AACGCCCACCCCAGTTTCTTC & & & \\
rs53576 & $224 \mathrm{bp}$ & ARMS
\end{tabular}

F: TGTGATTTGTACCCAGAAGG

R1: CCTGTTTCTGTGTGACTGAGGTT

R2: CCTGTTTCTGTGTGACTGAGGTC 
Saravani Ret al.

\subsection{Statistical Analysis}

The SPSS software version 16.0 (SPSS Inc., Chicago, IL, USA) was used for all the statistical analyses. The association between genotypes and T2D was estimated using the Odds Ratio (OR) and 95\% Confidence Intervals (95\% CI) from logistic regression analyses. The Hardy-Weinberg equilibrium was tested with the $\chi^{2}$ test for all of the Single Nucleotide Polymorphisms (SNPs) under consideration. The significance level was set at $\mathrm{P} \leq 0.05$ for all the tests.

\section{Results}

In this study, the allelic and genotypic distributions of OXTR polymorphism at position rs2254298 A/G were not significantly different between patients and controls (OR $=1.054$, \% 95 CI: $0.557-1.995, P=0.871)$, for the AG genotype; $\mathrm{OR}=1.004,95 \% \mathrm{CI}: 0.547-1.845, \mathrm{P}=1$ for the A allele). The AA genotype was not observed (Table 2).

On the other hand, the allele and genotype frequencies of rs53576 OXTR variant, in patients with T2D and controls

Table 2. Genotype and Allele Frequencies of Oxytocin Receptor rs2254298 Gene Polymorphism in Patients With Type 2 Diabetes and the Control Group

\begin{tabular}{lcccc}
\hline & Patients ${ }^{\mathrm{a}, \mathrm{b}}$ & Control $^{\mathrm{a}, \mathrm{b}}$ & Odds Ratio $(\mathbf{9 5} \% \mathbf{C I})$ & P Value \\
\hline Genotype & & & & - \\
\hline GG & $96(80)$ & $97(80.8)$ & $1($ Ref $)$ & 0.871 \\
AG & $24(20)$ & $23(19.2)$ & $1.054(0.557-1.995)$ & - \\
AA & $0(0.0)$ & $0(0.0)$ & - & - \\
Allele & & & Ref & 1.000 \\
\hline G & $216(90)$ & $217(90.4)$ & $1.004(0.547-1.845)$ & \\
\hline A & $23(10)$ & $23(9.6)$ & & \\
\hline
\end{tabular}

a Values are presented as No (\%).

$\mathrm{b} n=120$.

Figure 1. Electrophoresis Pattern of Restriction Fragment Length Polymorphism-Polymerase Chain Reaction (RFLP-PCR) for Detection of Oxytocin Receptor (rs2254298) A/G Polymorphism

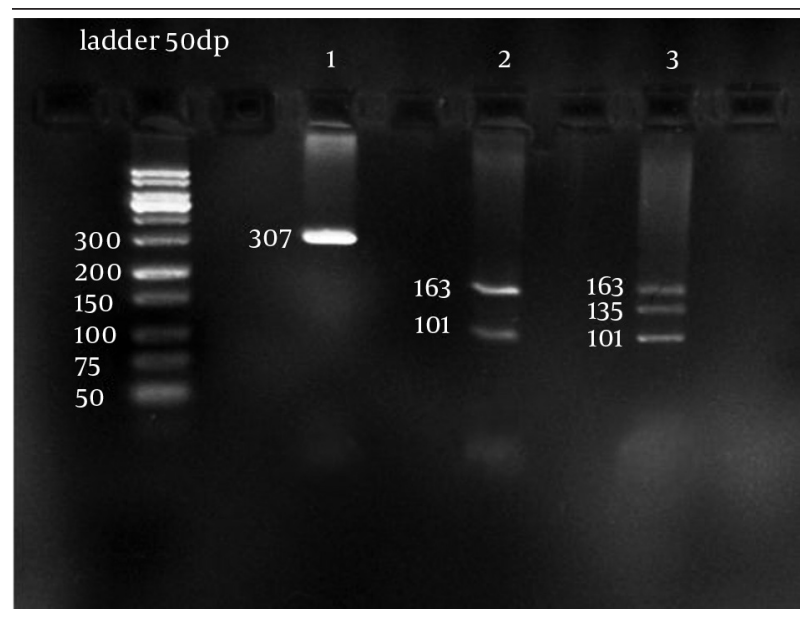

Product size: 307 bp, restriction enzyme: Bsrl, sample 2: G 9/163/34/101 bp, sample 3: AG 9/101/163/135 bp.
Figure 2. Electrophoresis Pattern of the Allele-Specific Primer (ASP)Polymerase Chain Reaction (PCR) for Detection of Oxytocin Receptor (rs53576) T/C Polymorphism

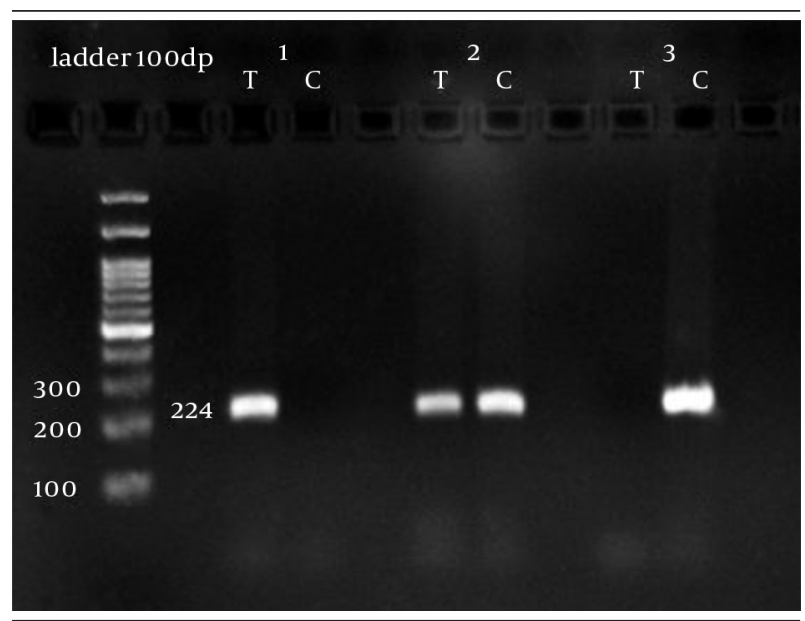

Product size: 224 bp, sample 1: T, sample 2:TC, sample 3: C.

Table 3. Genotype and Allele Frequencies of Oxytocin Receptor rs53576 Gene Polymorphism in Patients With Type 2 Diabetes and the Control Group

\begin{tabular}{lccc}
\hline & Patients $^{\mathrm{a}, \mathrm{b}}$ & Control $^{\mathrm{a}, \mathrm{b}}$ & Odds Ratio (95\% CI) $^{\text {P Value }}$ \\
\hline Genotype & & & $1($ Ref $)$ \\
CC & $50(41.7)$ & $38(31.7)$ & $0.76(0.42-1.34)$ \\
TC & $51(42.5)$ & $51(42.5)$ & $0.466(0.22-0.94)$ \\
TT & $19(15.8)$ & $31(25.8)$ & 0.035 \\
Allele & & $127(52.9)$ & Ref \\
C & $151(62.9)$ & $113(47.1)$ & $0.66(0.46-0.95)$ \\
\hline T & $89(37.1)$ & & 0.03 \\
\hline
\end{tabular}

${ }^{\mathrm{a}}$ Values are presented as No (\%).

b $\mathrm{n}=12$. 
(listed in Table 3) showed significant differences of distribution. The frequency of TT genotype was lower in patients compared to controls ( $15.8 \%$ versus $25.8 \%$ ), with the difference being statistically significant $(\mathrm{OR}=0.466,95 \%$ CI: $0.22-0.94, \mathrm{P}=0.035$ ).

The T allele, at position rs53576, had frequencies of 37.1\% and $47.1 \%$ in patients and controls, respectively (OR $=$ $0.66,95 \%$ CI: $0.46-0.95, P=0.003)$. Results of the HardyWeinberg equilibrium for all SNPs showed that the study population was in balance (data not shown).

\section{Discussion}

The aim of this study was to investigate the correlation between SNP candidate gene of OXTR and risk of T2D in a sample of the Iranian population. The results of this study showed a significant difference between the oxytocin receptor rs53576 (T/C) in genotype TT and T allele in the patient and control groups, emphasizing the protective role this receptor plays in T2D. However, the frequencies of the rs2254298 (A/G) OXTR gene, in the A genotype and allele, showed a negative association when analyzed against T2D risk factors.

Diabetes is the most common endocrine metabolic disorder that can reduce life expectancy by one-third (3). Diabetes affects over than 300 million people and this number will rise by 2030 (37). Poorly controlled diabetes leads to retinopathy, nephropathy and neuropathy. The T2D is a polygenic chronic disease and involves a multiple of factors, such as hormones (38). Oxytocin hormone has been implicated in socio-emotional behaviors (30), energy metabolism and also available data show that OXT in neurons can regulate the metabolic status of the body (38). Carbohydrate catabolism is modulated by oxytocin through its receptor in peripheral tissues. However, the role of OXTR polymorphism in T2D is unknown. A number of studies have shown that two of the SNP-OXTR are associated with some diseases. These SNPs are assumed to play a central role in the individual variability of stress reactivity, social behavior and autism $(35,39)$. For example, individuals with alleles A or AA in rs53576 of OXTR gene show reduced reactivity to high stress (40) and also present deficits in social behavior and in certain cases present autism (39). The heterozygous rs2254298 polymorphism show the highest levels of symptoms of depression (41), whereas the A allele of OXTR is associated with amygdala volume and autism $(42,43)$. Evidence on the associations between OXTR genotype rs2254298 and plasma concentration of OXT has been presented by previous reports (44). The data show that carriers of the A allele had increased OXT compared to the G allele. Limited studies have demonstrated the role of SNP of the OXTR gene in diabetes. Previous Whole-Genome Association (WGA) studies have shown an association between OXTR and perfect blood glucose homeostasis and thus an association with T2D in different ethnic groups. The WGA studies also indicated that SNP-OXTR could be regarded as a
T2D susceptibility gene (38). In this study, we used only a sample of the Iranian population.

Previous study populations were from the four countries with a prevalence of diabetes in the family. In our study, we used only a sample of the Iranian population and the results showed a susceptibility to T2D with oxytocin receptor gene polymorphism. The rs1042778 OXTR has been considered as a risk factor among pregnant Malaysian women with gestational diabetes mellitus (45). The SNP used in their study is different from that used by our study. In this study, we aimed to evaluate the oxytocin receptor gene polymorphisms in patients with diabetes in South East of Iran. In this study, we provide evidence that oxytocin receptor gene polymorphism is a susceptibility gene for patients with type 2 diabetes. Nevertheless, our findings showed that the TT genotype and the Tallele of rs53576 OXTR gene presented significant differences in the oxytocin gene polymorphisms in our population. Also, the rs2254298, in the A genotype and allele, showed a negative correlation with T2D. Therefore, it is suggested to study the OXTR in larger populations, with greater ethnic variability, so that the results could be confirmed.

\section{Acknowledgements}

The authors wish to thank the University of Sistan and Baluchestan, Zahedan, Ali Asghar clinic and the individuals who participated in this study.

\section{Authors' Contributions}

Elahe Esmaeeli and Ramin Saravani performed the data collection and laboratory work. Ramin Saravani, Mohammad Kordi Tamendani, Mehrnaz Narooie Nejad and Elahe Esmaeeli contributed to the study design, statistical analysis and interpretation of the results. All the authors read, modified and approved the final version of the manuscript.

\section{Funding/Support}

This project was funded by the University of Sistan and Baluchestan.

\section{References}

1. Alberti KG, Zimmet PZ. Definition, diagnosis and classification of diabetes mellitus and its complications. Part 1: diagnosis and classification of diabetes mellitus provisional report of a WHO consultation. Diabet Med.1998;15(7):539-53.

2. Henriksen EJ, Diamond-Stanic MK, Marchionne EM. Oxidative stress and the etiology of insulin resistance and type 2 diabetes. Free Radic Biol Med. 2011;51(5):993-9.

3. Wild S, Roglic G, Green A, Sicree R, King H. Global prevalence of diabetes: estimates for the year 2000 and projections for 2030 . Diabetes Care. 2004;27(5):1047-53.

4. Kitabchi AE, Umpierrez GE, Miles JM, Fisher JN. Hyperglycemic crises in adult patients with diabetes. Diabetes Care 2009;32(7):1335-43.

5. Kahn SE. The relative contributions of insulin resistance and beta-cell dysfunction to the pathophysiology of Type 2 diabetes. Diabetologia. 2003;46(1):3-19. 
6. Chiasson JL, Aris-Jilwan N, Belanger R, Bertrand S, Beauregard $\mathrm{H}$, Ekoe JM, et al. Diagnosis and treatment of diabetic ketoacidosis and the hyperglycemic hyperosmolar state. CMAJ. 2003;168(7):859-66.

7. Zhou J, Zhou S, Zeng S. Experimental diabetes treated with trigonelline: effect on beta cell and pancreatic oxidative parameters. Fundam Clin Pharmacol. 2013;27(3):279-87.

8. Engum A. The role of depression and anxiety in onset of diabetes in a large population-based study. J Psychosom Res. 2007;62(1):31-8.

9. Chen FS, Kumsta R, von Dawans B, Monakhov M, Ebstein RP, Heinrichs $\mathrm{M}$. Common oxytocin receptor gene (OXTR) polymorphism and social support interact to reduce stress in humans. Proc Natl Acad Sci U S A. 2011;108(50):19937-42.

10. Marazziti D, Catena Dell'osso M. The role of oxytocin in neuropsychiatric disorders. Curr Med Chem. 2008;15(7):698-704.

11. Slattery DA, Neumann ID. Chronic icv oxytocin attenuates the pathological high anxiety state of selectively bred Wistar rats. Neuropharmacology. 2010;58(1):56-61.

12. Florian M, Jankowski M, Gutkowska J. Oxytocin increases glucose uptake in neonatal rat cardiomyocytes. Endocrinology. 2010;151(2):482-91.

13. Hamden K, Bengara A, Amri Z, Elfeki A. Experimental diabetes treated with trigonelline: effect on key enzymes related to diabetes and hypertension, beta-cell and liver function. Mol Cell Biochem. 2013;381(1-2):85-94.

14. Kitabchi AE, Umpierrez GE, Murphy MB, Barrett EJ, Kreisberg RA Malone JI, et al. Management of hyperglycemic crises in patients with diabetes. Diabetes Care. 2001;24(1):131-53.

15. Abdul-Ghani MA, Matsuda M, Sabbah M, Jenkinson CP, Richardson DK, Kaku K, et al. The relative contributions of insulin resistance and beta cell failure to the transition from normal to impaired glucose tolerance varies in different ethnic groups. Diabetes \& Metabolic Syndrome: Clinical Research \& Reviews. 2007;1(2):105-12.

16. Morton GJ, Thatcher BS, Reidelberger RD, Ogimoto K, WoldenHanson T, Baskin DG, et al. Peripheral oxytocin suppresses food intake and causes weight loss in diet-induced obese rats. Am J Physiol Endocrinol Metab. 2012;302(1):E134-44.

17. Zhang $\mathrm{H}, \mathrm{Wu} \mathrm{C}$, Chen Q, Chen X, Xu Z, Wu J, et al. Treatment of obesity and diabetes using oxytocin or analogs in patients and mouse models. PLoS One. 2013;8(5):e61477.

18. Alrefai H, Allababidi H, Levy S, Levy J. The endocrine system in diabetes mellitus. Endocrine. 2002;18(2):105-19.

19. Kolesnik Yu M, Orestenko Yu N, Abramov AV. State of the vasopressin-, oxytocin-, and corticoliberin-synthesizing structures of the hypothalamus in experimental diabetes in rats of both sexes. Neurosci Behav Physiol. 1994;24(2):163-6.

20. Ikawa H, Irahara M, Matsuzaki T, Saito S, Sano T, Aono T. Impaired induction of prolactin secretion from the anterior pituitary by suckling in streptozotocin-induced diabetic rat. Acta Endocrinol (Copenh). 1992;126(2):167-72

21. Olszewski PK, Klockars A, Schioth HB, Levine AS. Oxytocin as feeding inhibitor: maintaining homeostasis in consummatory behavior. Pharmacol Biochem Behav. 2010;97(1):47-54.

22. Heinrichs M, Baumgartner T, Kirschbaum C, Ehlert U. Social support and oxytocin interact to suppress cortisol and subjective responses to psychosocial stress. Biol Psychiatry. 2003;54(12):138998.

23. Ditzen B, Schaer M, Gabriel B, Bodenmann G, Ehlert U, Heinrichs M. Intranasal oxytocin increases positive communication and reduces cortisol levels during couple conflict. Biol Psychiatry. 2009;65(9):728-31.

24. Quirin M, Kuhl J, Dusing R. Oxytocin buffers cortisol responses to stress in individuals with impaired emotion regulation abilities. Psychoneuroendocrinology. 2011;36(6):898-904.

25. Zhang G, Bai H, Zhang H, Dean C, Wu Q, Li J, et al. Neuropeptide exocytosis involving synaptotagmin-4 and oxytocin in hypothalamic programming of body weight and energy balance. Neuron.
2011;69(3):523-35.

26. Elmquist JK, Coppari R, Balthasar N, Ichinose M, Lowell BB. Identifying hypothalamic pathways controlling food intake, body weight, and glucose homeostasis.JComp Neurol.2005;493(1):63-71.

27. Zhang G, Cai D. Circadian intervention of obesity development via resting-stage feeding manipulation or oxytocin treatment. Am J Physiol Endocrinol Metab. 2011;301(5):E1004-12.

28. Insel TR. Oxytocin--a neuropeptide for affiliation: evidence from behavioral, receptor autoradiographic, and comparative studies. Psychoneuroendocrinology. 1992;17(1):3-35.

29. Tribollet E, Dubois-Dauphin M, Dreifuss JJ, Barberis C, Jard S. Oxytocin receptors in the central nervous system. Distribution, development, and species differences. Ann N Y Acad Sci. 1992;652:29-38.

30. Gimpl G, Fahrenholz F. The oxytocin receptor system: structure, function, and regulation. Physiol Rev. 2001;81(2):629-83.

31. English P, Williams G. Hyperglycaemic crises and lactic acidosis in diabetes mellitus. Postgrad Med J. 2004;80(943):253-61.

32. Swaab DF, Purba JS, Hofman MA. Alterations in the hypothalamic paraventricular nucleus and its oxytocin neurons (putative satiety cells) in Prader-Willi syndrome: a study of five cases. The Journal of Clinical Endocrinology \& Metabolism. 1995;80(2):573-9.

33. Leng G, Onaka T, Caquineau C, Sabatier N, Tobin VA, Takayanagi Y. Oxytocin and appetite. Prog Brain Res. 2008;170:137-51.

34. Olson BR, Drutarosky MD, Stricker EM, Verbalis JG. Brain oxytocin receptor antagonism blunts the effects of anorexigenic treatments in rats: evidence for central oxytocin inhibition of food intake. Endocrinology. 1991;129(2):785-91.

35. Onaka T, Takayanagi Y, Yoshida M. Roles of oxytocin neurones in the control of stress, energy metabolism, and social behaviour. $J$ Neuroendocrinol. 2012;24(4):587-98.

36. Kuessel L, Grimm C, Knofler M, Haslinger P, Leipold H, Heinze G, et al. Common oxytocin receptor gene polymorphisms and the risk for preterm birth. Dis Markers. 2013;34(1):51-6.

37. Whiting DR, Guariguata L, Weil C, Shaw J. IDF diabetes atlas: global estimates of the prevalence of diabetes for 2011 and 2030 Diabetes Res Clin Pract. 2011;94(3):311-21.

38. Salonen JT, Uimari P, Aalto JM, Pirskanen M, Kaikkonen J, Todorova B, et al. Type 2 diabetes whole-genome association study in four populations: the DiaGen consortium. Am J Hum Genet. 2007;81(2):338-45.

39. Kogan A, Saslow LR, Impett EA, Oveis C, Keltner D, Rodrigues Saturn S. Thin-slicing study of the oxytocin receptor (OXTR) gene and the evaluation and expression of the prosocial disposition. Proc Natl Acad Sci U S A. 2011;108(48):19189-92.

40. Rodrigues SM, Saslow LR, Garcia N, John OP, Keltner D. Oxytocin receptor genetic variation relates to empathy and stress reactivity in humans. Proc Natl Acad Sci U S A. 2009;106(50):21437-41.

41. Thompson RJ, Parker KJ, Hallmayer JF, Waugh CE, Gotlib IH. Oxytocin receptor gene polymorphism (rs2254298) interacts with familial risk for psychopathology to predict symptoms of depression and anxiety in adolescent girls. Psychoneuroendocrinology. 2011;36(1):144-7.

42. Inoue $\mathrm{H}$, Yamasue $\mathrm{H}$, Tochigi M, Abe O, Liu X, Kawamura Y, et al. Association between the oxytocin receptor gene and amygdalar volume in healthy adults. Biol Psychiatry. 2010;68(11):1066-72.

43. Liu X, Kawamura Y, Shimada T, Otowa T, Koishi S, Sugiyama T, et al. Association of the oxytocin receptor (OXTR) gene polymorphisms with autism spectrum disorder (ASD) in the Japanese population. J Hum Genet. 2010;55(3):137-41.

44. Feldman R, Zagoory-Sharon O, Weisman O, Schneiderman I, Gordon I, Maoz R, et al. Sensitive parenting is associated with plasma oxytocin and polymorphisms in the OXTR and CD38 genes. Biol Psychiatry. 2012;72(3):175-81.

45. Ismail NAM, Aris NM, Mahdy ZA, Ahmad S, Naim NM, Siraj HH, et al. Single Nucleotide Polymorphism for Certain Genes Involved in Gestational Diabetes with Risk Factors and Complications Positive. Sains Malaysiana. 2013;42(11):1613-8. 